\title{
Stomatal conductivity, canopy temperature and evapotranspiration of maize (Zea mays L.) to water stress in Northeast China
}

\author{
Haijun Liu ${ }^{1 *}$, Zhuangzhuang Gao ${ }^{1}$, Liwei Zhang ${ }^{1}$, Yu Liu ${ }^{2}$ \\ (1. Beijing Key Laboratory of Urban Hydrological Cycle and Sponge City Technology, College of Water Sciences, \\ Beijing Normal University, Beijing 100875, China; \\ 2. School of Civil Engineering and Hydraulic Engineering, Ningxia University, Yinchuan 750021, China)
}

\begin{abstract}
The Northeast China Plain (NECP) is one of the main maize (Zea mays L.) production regions in China but is now subject to drought because of climate change and a rain-fed cultivation system. A two-year experiment was conducted in a typical maize cultivation region in the NECP to investigate the responses of plant physiological factors and evapotranspiration (ET) to water stresses at different growth stages. Results show that the responses of plant physiological factors to water stress can be divided into three levels based on soil water content $(S W C)$ in the main root zone: when $S W C$ was greater than $0.22 \mathrm{~cm}^{3} / \mathrm{cm}^{3}$ (equivalent to $62 \%$ field capacity (FC)), stomatal conductivity $\left(g_{s}\right)$ and $E T$ reached their highest values, and the canopy temperature $\left(T_{c}\right)$ was close to the air temperature; when $S W C$ was within $0.15-0.22 \mathrm{~cm}^{3} / \mathrm{cm}^{3}\left(43 \%-62 \%\right.$ FC), the $g_{s}$ and $E T$ decreased, and $T_{c}$ increased as $S W C$ decreased; and when $S W C$ was lower than $0.15 \mathrm{~cm}^{3} / \mathrm{cm}^{3}\left(<43 \%\right.$ FC), $g_{s}$ and $E T$ reached their lowest values and $T_{c}$ was greater than 1.2 times the air temperature. The ratio of canopy temperature to air temperature $\left(R_{T}\right)$, is closely related to stomatal conductivity and soil water content, and especially linearly related to crop water stress index $(C W S I)$, and can be used as an alternative to CWSI for evaluating maize water stress because of easily data achieving and simple calculation processes. In a conclusion, $R_{T}$ of 1.2 can be used as an index to identify a severe water stress status, and maintaining $S W C$ greater than $60 \% \mathrm{FC}$ at the heading and grain-filling stages is important for supporting maize normal $E T$ and growth in the study region.
\end{abstract}

Keywords: water stress, drought indices, canopy temperature, crop evapotranspiration, stoma conductivity, maize, soil water DOI: $10.25165 /$ j.ijabe.20211402.5289

Citation: Liu H J, Gao Z Z, Zhang LW, Liu Y. Stomatal conductivity, canopy temperature and evapotranspiration of maize (Zea mays L.) to water stress in Northeast China. Int J Agric \& Biol Eng, 2021; 14(2): 112-119.

\section{Introduction}

The Northeast China Plain (NECP) includes Liaoning Province, Jilin Province and Heilongjiang Province and is one of main grain production regions in China. In 2017, the total maize grain production in the NECP was 87.4 million $t$ and accounted for $33.8 \%$ of all maize grain production in China (259.1 million $\mathrm{t}$ ). The average maize yield per hectare in the NECP was $6874 \mathrm{~kg}$, which is $12.5 \%$ higher than the national value $\left(6110 \mathrm{~kg} / \mathrm{hm}^{2}\right)$. Maize yields greater than $10 \mathrm{t} / \mathrm{hm}^{2}$ in the NECP were also reported $^{[1]}$. Therefore, the high maize grain production in the NECP is the basis for food security in China.

Because of plentiful precipitation and radiation in NECP, most maize fields have no irrigation systems, and the traditional cropping system for maize is rainfed ${ }^{[2,3]}$. In this case, maize production in the NECP is subject to climate change ${ }^{[3-6]}$. Over the past 50 years, the climate in NECP was generally getting warmer and drier, with the precipitation amount decreasing and evaporation potential increasing in most regions ${ }^{[4,7]}$. Droughts occurred

Received date: 2019-07-15 Accepted date: 2020-10-31

Biographies: Zhuangzhuang Gao, Master, research interests: agricultural water use, Email: bnugaozz@mail.bnu.edu.cn; Liwei Zhang, Master, research interests: irrigation and drainage engineering, Email: zlwaie@126.com; Yu Liu, Master, research interests: irrigation, drainage engineering and climate change, Email: liuyu098@163.com.

*Corresponding author: Haijun Liu, $\mathrm{PhD}$, Professor, research interests: agricultural water management and fertigation engineering. 19\# Xinwai St. College of Water Sciences, Beijing Normal University, Beijing 100875, China. Tel: +86-13681334108, Email: shanxilhj@bnu.edu.cn. frequently, which represent some of the most important meteorological disasters in the $\mathrm{NECP}^{[4,8,9]}$. For example, in 2000, 2007 and 2009, fields in the NECP that suffered from drought totaled 9.3, 11.6 and 9.4 million $\mathrm{hm}^{2}$ and correspondingly resulted in grain yield reductions of $38.0 \%, 32.6 \%$, and $22.2 \%$, respectively ${ }^{[10]}$. Khan et al. ${ }^{[11]}$ predicted extreme drought events in the future (2016-2099) and reported a long period of drought from 2060-2099 in the NECP. Therefore, accurate and timely identification of water stress for maize is important for choosing methods to reduce the impact of drought on crop growth and yield.

Maize is sensitive to water stress, especially given the high yield objective. Published literature has shown that water stress does greatly affect maize growth and yield. After a three-year experiment in Vojvodina in Northern Serbia, Kresović et al. ${ }^{[12]}$ reported that the mean maize grain yield was reduced by $10 \%-30 \%$ with a $25 \%-100 \%$ irrigation water reduction compared to full irrigation. Wang et al. ${ }^{[13]}$ reported after a pot experiment that maize evapotranspiration decreased by $40 \%$ and $53 \%$ and that dry biomasses decreased by $34 \%$ and $50 \%$ by controlling the soil water content at $60 \%$ and $40 \%$ of field capacity, respectively, compared to full irrigation. Compared to irrigated land, the maize yields in rain-fed land were reduced by more than $55 \%$ and suffered much greater year-to-year variability due to climate and precipitation variation $^{[14-17]}$. Kerridge et al. ${ }^{[18]}$ reported that precipitation is a limiting factor in achieving high yields in the Northeast region as well as most regions in China. They predicted a potential maize yield in a water-limited region as $10.7 \mathrm{t} / \mathrm{hm}^{2}$, which is much lower than the yield of $14.2 \mathrm{t} / \mathrm{hm}^{2}$ in water sufficient conditions. Therefore, evaluating and then reducing water stress is important 
for maintaining a high maize yield.

Physiological indices, including canopy/stomata conductance, leaf potential, and canopy temperature are sensitive to water stress and therefore are used to evaluate the water stress status ${ }^{[19,20]}$. Among these indices, canopy temperature has been studied for crops, orchards trees and forests ${ }^{[21-23]}$. Han et al. ${ }^{[24-27]}$ measured the temperature differences between the sunlit and shaded parts of a maize canopy to estimate the maize water stress. They found that the temperature differences increased as the leaf water potential decreased and soil water deficit increased, while the differences decreased when stomatal conductance increased. Based on canopy temperature, a crop water stress index, CWSI, was proposed to evaluate the water stress condition. To calculate CWSI, canopy temperatures in real conditions, non-water-stress conditions and conditions where transpiration has completely halted are required because canopy temperatures in the latter two conditions vary according to maize growth and climate condition $^{[22,28-30]}$. Therefore, there is greater uncertainty when using the CWSI indices reported in a region to evaluate crop stress in another region. Hence a simple and robust temperature-based water stress index could be practical to help farmers to evaluate water stress status.

In this study, a two-year experiment was conducted in the NECP to investigate the responses of maize's physiological factors and evapotranspiration to water stress, and propose a simple and reliable indicator to evaluate the crop water stress status. The results of this study will help farmers and agricultural extension administrators to manage maize fields efficiently to achieve a high yield in the NECP.

\section{Material and methods}

\subsection{Experimental site}

A two-year experiment (the 2014 and 2015 seasons) was conducted at the Lishu Experimental Station at China Agricultural University $\left(124^{\circ} 26^{\prime} 9^{\prime \prime} \mathrm{E}, 43^{\circ} 16^{\prime} 47^{\prime \prime} \mathrm{N}, 171 \mathrm{~m}\right.$ above mean sea level), located in Siping City, Jilin Province, Northeast China. The Siping region is a typical maize cultivation region in Northeast China $^{[31]}$. In 2014, the maize cultivation area accounted for $93.7 \%$ of the total farmland in the Siping region. The climate in this region is a typical sub-humid continental climate. The annual mean temperature is $6.5^{\circ} \mathrm{C}$, the wind speed is $3.0 \mathrm{~m} / \mathrm{s}$, and the annual total sunshine hour is $2700 \mathrm{~h}$. The mean annual rainfall is $631 \mathrm{~mm}$, and more than $70 \%$ occurs from July to September. Recently, great climate variation has been observed in this region, including significant trends of temperature increases and radiation decreases ${ }^{[32]}$. This change may greatly affect maize production.

The soil texture is uniform over the root zone in the research region. In the $0-100 \mathrm{~cm}$ depth, the soil texture is a silty clay loam with $14.8 \%$ sand, $49.1 \%$ silt and $36.1 \%$ clay. The bulk densities in the $0-20 \mathrm{~cm}$ soil layer were measured as $1.41 \mathrm{~g} / \mathrm{cm}^{3}$ and $1.53 \mathrm{~g} / \mathrm{cm}^{3}$ in the $20-100 \mathrm{~cm}$ soil layer. The average saturated water content, field capacity (FC) and permanent wilting point (PWP) in the $0-100 \mathrm{~cm}$ depth were measured as $0.40-0.46 \mathrm{~cm}^{3} / \mathrm{cm}^{3}$, $0.35-0.36 \mathrm{~cm}^{3} / \mathrm{cm}^{3}$ and $0.07-0.09 \mathrm{~cm}^{3} / \mathrm{cm}^{3}$, respectively.

\subsection{Experimental design}

The experiment was conducted from May to September in the 2014 and 2015 maize growth periods. During each maize growth season, water stress treatments were set in the elongation stage (S1), heading stage (S2), and grain-filling stage (S3). Four water treatments were conducted depending on the soil water status and duration of the water stress days. The start point of water stress was set when the soil water content is lower than the $60 \%$ FC following the standards of "Grade of Agricultural Drought" and "Grades of Meteorological Drought" ${ }^{[33,34]}$.

Treatment T1: irrigating plants when soil water content is just found at $60 \%$ FC. In this case, soil water is higher than $60 \%$ FC and sufficient, then maize plants don't suffer water stress ${ }^{[33,34]}$; The total irrigation events were 54 and 55 times in the 2014 and 2015 experimental seasons, respectively;

Treatment T2: irrigating plants 2-3 d after T1, then maintain full irrigation in the following growth periods;

Treatment T3: irrigating plants 2-3 d after T2, or 4-6 d after T1, then maintain full irrigation in the following growth periods;

Treatment T4: irrigating plants 2-3 d after T3, or after 6-8 d after $\mathrm{T} 1$, then maintain full irrigation in the following growth periods.

Three replications occurred for each treatment.

To precisely control the soil water and irrigation, the maize plants were cultivated in round buckets $50 \mathrm{~cm}$ in diameter and $60 \mathrm{~cm}$ in height. The soil in these buckets was taken from the $0-20 \mathrm{~cm}$ soil layer in the experimental station. It was firstly dried on ground under natural conditions, then screened through a $2 \mathrm{~mm}$ pore sieve and mixed to prepare a uniform soil texture for all plants, lastly filled into the buckets. The height from the soil surface to the upper rim of the bucket was approximately $10 \mathrm{~cm}$. The soil bulk density in the bucket was $1.4 \mathrm{~g} / \mathrm{cm}^{3}$, the saturated soil water content was $0.42 \mathrm{~cm}^{3} / \mathrm{cm}^{3}$, and the field capacity was $0.35 \mathrm{~cm}^{3} / \mathrm{cm}^{3}$, thus replicating the soil physical properties in the field. In both years, the maize variety Liangyu 11, a widely cultivated variety in this region, was used. Three maize seeds were planted in each bucket at a 3-4 $\mathrm{cm}$ depth on May 1 for both seasons. When the plant grew 2-3 leaves, only one plant was kept, and other plants were removed from each bucket.

When preparing the soil to fill the buckets, $12 \mathrm{~g}$ of compound fertilizer $\left(\mathrm{N}: \mathrm{P}_{2} \mathrm{O}_{5}: \mathrm{K}_{2} \mathrm{O}=24 \%: 13 \%: 15 \%\right)$ was applied per bucket. This applied amount was based on local practice and was sufficient to support maize growth in a season. Therefore, there was no top-dressing fertilizer in either season. The soil in these buckets was covered with a plastic sheet to reduce soil evaporation through the growth season. On rainy days, a rain shelter was used to protect the bucket from the rain.

All plants were irrigated with a drip irrigation system. Two drippers with a drip discharge of $2.3 \mathrm{~L} / \mathrm{h}$ with a pressure of $0.1 \mathrm{MPa}$ were deployed in each bucket for irrigation application. From the sowing to elongation stage (around late June), all plants were fully irrigated for growth. Thereafter, the plants were irrigated following the experimental design. The controlled upper soil water content for irrigation was approximately $90 \%$ FC. Additionally, the irrigation amount for each treatment was calculated using the measured soil water content and the controlled upper limit soil water content. The real irrigation amount was measured with a water meter deployed in the main pipe of this drip irrigation system. The irrigation water was pumped from a well in the experimental station.

\subsection{Measurements and calculation}

\subsubsection{Soil water}

The soil water content was measured using the $\mathrm{ECH}_{2} \mathrm{O}$ system (Decagon Devices, Inc., USA). Each $\mathrm{ECH}_{2} \mathrm{O}$ system has three probes, separately installed at $10 \mathrm{~cm}, 20 \mathrm{~cm}$ and $40 \mathrm{~cm}$ depths in the soil. The mean data of these three probes were used as the soil water content in the measured bucket. In each measurement, 12 sets of $\mathrm{ECH}_{2} \mathrm{O}$ systems were installed in 12 buckets, with one set in 
a bucket. The soil water content was only measured for plants during the water stress period. For plants in T1, the soil water content was measured in all growth seasons.

\subsubsection{Stomatal conductivity}

Stomatal conductivity was measured at the second or third full-grown leaf from the top down at approximately 12:00 using a Leaf Porometer (Model SC-1, Decagon Devices, Inc., USA). On the measured leaf, three points which were $1 / 4,2 / 4$ and 3/4 in leaf length were selected for stomatal conductivity measurement. The mean value of the three measurements for the same leaf was used for data analysis. Stomatal conductivity was measured in each replicated plant during the set water stress period.

\subsubsection{Canopy temperature}

The canopy temperatures of the three replicated plants in each treatment were measured at approximately 12:00 using a Thermal Imager (Model Ti200, Fluke Corp., USA). Only the plant canopy area in the image was selected, and the mean canopy temperature was then calculated.

\subsubsection{Crop evapotranspiration}

Twelve electrical balances, three for each treatment, were prepared to measure the mass change of each bucket with maize plant. The mass change was used to calculate the plant evapotranspiration $(E T)$ and irrigation amount. The rain amount was not considered because a rain shelter was used to prevent rain from falling into the buckets. The data were sampled at $15 \mathrm{~min}$ and stored in a data logger. These data were downloaded to a laptop computer for crop ET analysis.

\subsubsection{Climate measurement}

In the two experimental seasons (i.e., from May to September in 2014 and 2015), climate factors, including air temperature, relative humidity, solar radiation, and wind speed at a 2-m height above the ground surface, were measured at an automatic weather station (HOBO, Campbell Scientific Inc., USA) located approximately $50 \mathrm{~m}$ away from the experimental site. The data were sampled at 1-minute intervals and stored at 15-minute intervals and were then downloaded periodically to obtain the daily mean values.

\subsubsection{Crop Water Stress Index}

The crop water stress index (CWSI) was computed from the measured canopy temperatures and air temperatures using the following equation ${ }^{[26,27,35-37]}$ :

$$
\mathrm{CWSI}=\frac{\Delta T_{m}-\Delta T_{L L}}{\Delta T_{U L}-\Delta T_{L L}}
$$

where, $\Delta T_{m}$ is the difference between the measured canopy temperature $\left(T_{c},{ }^{\circ} \mathrm{C}\right)$ and air temperature $\left(T_{a},{ }^{\circ} \mathrm{C}\right),{ }^{\circ} \mathrm{C} ; \Delta T_{L L}$ is the lower limit difference between the canopy temperature and air temperature when plants grow in well-watered and non-water-stress conditions, ${ }^{\circ} \mathrm{C}$; and $\Delta T_{U L}$ is the upper limit difference between the canopy temperature and air temperature when plants suffer from severe water stress with transpiration reaching zero, ${ }^{\circ} \mathrm{C}$. In this study, the values of $\Delta T_{L L}$ was determined using data from $\mathrm{T} 1$ where maize was controlled under non-water stress condition, and $\Delta T_{U L}$ using the data measured in $\mathrm{T} 4$ where plant was always suffering great water stress condition, and results are shown in Figure 1. $\Delta T_{U L}$ varied from $3.54^{\circ} \mathrm{C}$ to $6.25^{\circ} \mathrm{C}$ with an average of $4.79^{\circ} \mathrm{C}$, and $\Delta T_{L L}$ decreased linearly with $V P D$ with a regressed line: $\Delta T_{L L}=-0.91 V P D+3.74$.

\subsection{Statistical analysis}

The measured data, including canopy temperature, stomatal conductivity and plant evapotranspiration were statistically analyzed using the IBM SPSS Statistics software package (version
20.0, IBM Corp., USA). The means' differences among treatments were tested using the least significant difference (LSD) at the 5\% level. Excel 2013 (Version: Microsoft Office 2013, Microsoft Corp., USA) was used to prepare the figures.

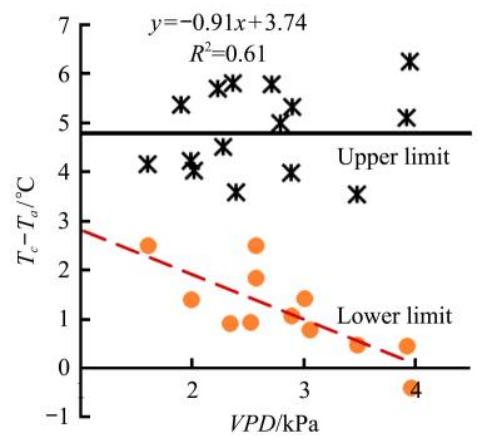

Note: Data in the upper line was achieved from T4 where maize suffered severe water stress, and data in the lower limit was from $\mathrm{T} 1$ where maize was grown under non-water stress conditions.

Figure 1 Relationships between measured temperature difference between canopy and air $\left(T_{c}-T_{a}\right)$ and vapor pressure deficit $(V P D)$ of maize from elongation to grain-milking stages in 2015 season

\section{Results}

\subsection{Stomatal conductivity}

Stomatal conductivity represents the opening condition of stomas. High stomatal conductivity means full opening stomas and high evapotranspiration and photosynthesis rates. Under water-sufficient conditions, stomatal conductivity varies with climate conditions and is especially controlled by radiation ${ }^{[38,39]}$. In the study region, stomatal conductivity increased from 6:00 to 12:00, after that point decreases gradually and reached approximately zero when radiation also reached zero at 18:00. Therefore, stomatal conductivity was measured at its maximum value, approximately 12:00 for each plant in this study.

Figure 2 shows stomatal conductivity changes at each treatment in the elongation stage and heading stage in the 2015 season. Generally, stomatal conductivity was significantly $(p<0.05)$ lower when plants suffered from soil water stress and then increased to or reached its maximum values when the plant was re-irrigated. At times, stomatal conductivity after re-irrigation for extreme water stressed treatments (for example, T3 and T4) was greater than those for fully irrigated plants (for example, T1). This may be due to the plant's water compensation effect ${ }^{[40,41]}$. $\mathrm{Yu}^{[42]}$ reported a significant compensatory elevation of stomatal conductance of the maize plants after water recovery in the mild and severe water stress conditions. The maize plants in the T4 treatment suffered from the greatest water stress with the longest non-irrigation period and consequently has the lowest stomatal conductivity before re-irrigation.

Water stress was the main reason for the stoma closing and the subsequent stomatal conductivity decrease. Therefore, the relationship between stomatal conductivity and soil water content was analyzed. In this analysis, only data on clear days were used because cloudy days may reduce solar radiation and thus stomatal conductivity. It can be seen in Figure 3 that in both seasons, stomatal conductivity generally increased with soil water content increases. Their relationship has three statuses based on soil water content. When the soil water content was greater than $0.22 \mathrm{~cm}^{3} / \mathrm{cm}^{3}$, stomatal conductivity was generally approximately $300 \mathrm{mmol} /\left(\mathrm{m}^{2} \cdot \mathrm{s}\right)$, indicating full growth and well-watered conditions. When the soil water content ranged from 0.15 to $0.22 \mathrm{~cm}^{3} / \mathrm{cm}^{3}$, stomatal conductivity varied greatly from 50 to 
$300 \mathrm{mmol} /\left(\mathrm{m}^{2} \cdot \mathrm{s}\right)$. When the soil water content was lower than $0.15 \mathrm{~cm}^{3} / \mathrm{cm}^{3}$, stomatal conductivity was generally smaller than $50 \mathrm{mmol} /\left(\mathrm{m}^{2} \cdot \mathrm{s}\right)$, indicating great water stress conditions. Han ${ }^{[19]}$ reported stomatal conductance greater than $500 \mathrm{mmol} /\left(\mathrm{m}^{2} \cdot \mathrm{s}\right)$ under no water stress and less than $200 \mathrm{mmol} /\left(\mathrm{m}^{2} \cdot \mathrm{s}\right)$ under severe water

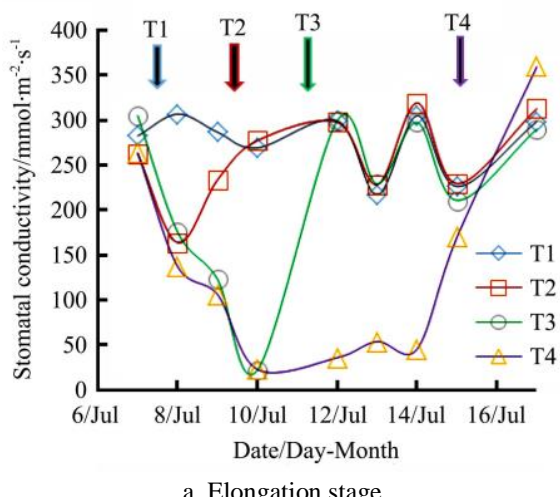

a. Elongation stage stress conditions. $\quad \mathrm{Yu}^{[42]}$ reported a stomatal conductivity range of 250-300 $\mathrm{mmol} /\left(\mathrm{m}^{2} \cdot \mathrm{s}\right)$ under water-sufficient conditions. The differences in stomatal conductance between this study and other studies may be due to plant species variation, climate conditions and the designated water stress category.

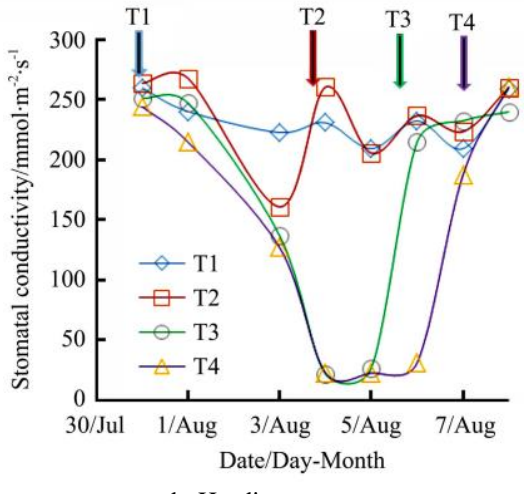

b. Heading stage

Figure 2 Stomatal conductivities at the elongation and heading stages for each water stress treatment in the 2015 season, symbol $\downarrow$ represents the re-watering day for the corresponding treatment
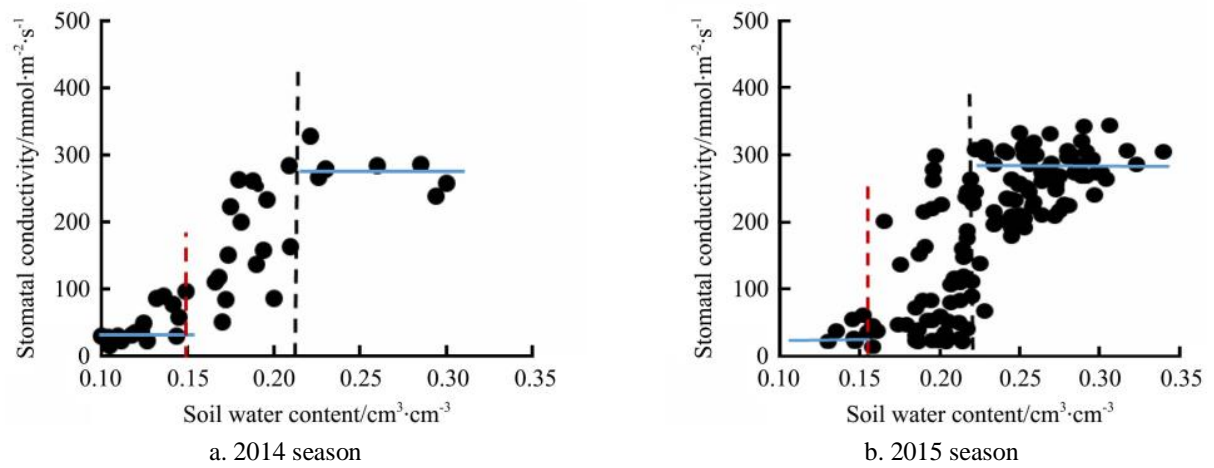

Figure 3 Relationship between stomatal conductivity measured at 12:00 and mean daily soil water content in the 2014 and 2015 seasons. Blue solid lines on the figures represent the mean values of the stomatal conductivity in the corresponding soil water content range

\subsection{Canopy temperature}

Canopy temperature is a sensitive factor used to evaluate crop water conditions ${ }^{[19,27]}$. Canopy temperature $\left(T_{c}\right)$, the difference in canopy and air temperatures $\left(\Delta T_{m}\right)$ and the ratio of canopy to air temperatures $\left(R_{T}\right)$ generally increased with the soil water content decreasing, indicating a greater increase in the degree of plant water stress. However, in the same soil water conditions, $T_{c}$ and $\Delta T_{m}$ were lower on cloudy days than on sunny days, which means that the measured absolute values of $T_{c}$ and $\Delta T_{m}$ are closely related to the environmental condition, especially air temperature. Therefore, $R_{T}$ was used to eliminate the effects of the environment's effect on the canopy temperature. The results show that $R_{T}$ is closely related to the soil water content.

Figure 4 shows the relationships between $R_{T}$ and soil water content at the four growth periods in the 2015 season. The data in the 2014 season showed a similar result and is therefore not presented in the figures. Figure 4 shows that the responses of canopy temperatures to the soil water content in the four stages showed a similar relationship, and their relationships can be classified into three stages according to the soil water content. In the first stage, the soil water content was greater than $0.22 \mathrm{~cm}^{3} / \mathrm{cm}^{3}$ and the canopy temperature was close to the air temperature. This means that $R_{T}$ is approximately 1.0 under well soil water condition, in which the maize is growing healthily. In the third stage, the soil water content was lower than $0.15 \mathrm{~cm}^{3} / \mathrm{cm}^{3}$, and $R_{T}$ is approximately 1.2. On sunny days, the canopy temperature reached

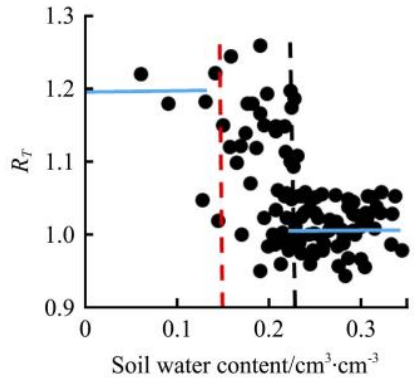

a. First half elongation stage

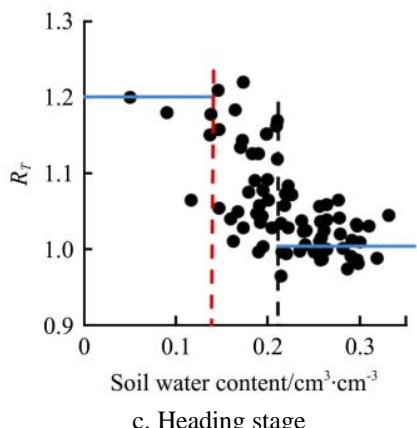

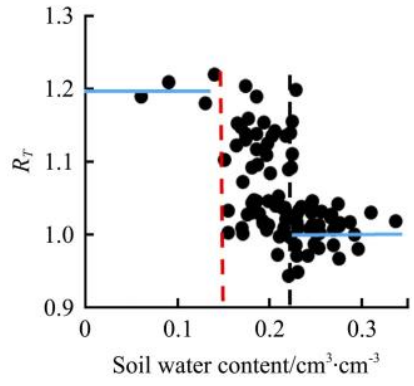

b. Second half elongation stage

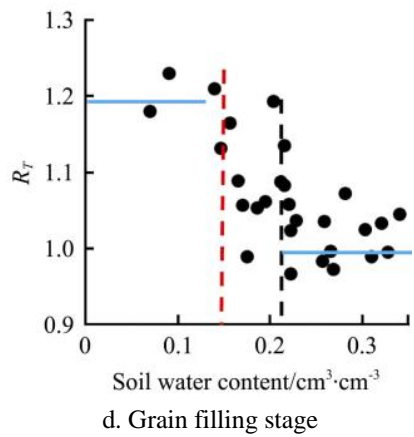

Note: Blue solid lines on the figures represent the mean values of the ratio of canopy to air temperatures in the corresponding soil water content range.

Figure 4 Relationship between ratio of canopy to air temperatures $\left(R_{T}\right)$ and soil water contents in the four growth stages of maize in the 2015 season 
$35^{\circ} \mathrm{C}$ when the air temperature was approximately $30^{\circ} \mathrm{C}$. This indicates the plants suffered from severe water stress and required a timely water application. Between the first and third stages is the second stage, in which the soil water content ranged from 0.15 to $0.22 \mathrm{~cm}^{3} / \mathrm{cm}^{3}$, and $R_{T}$ mostly ranged from 1.0 to 1.2 . The great variation of canopy temperatures in this soil water range may be due to the plants' adjustment in coping with water stress. When soil water continued to decrease and reached the third stage, the plants could lose their adjustment ability and demonstrated an extremely high canopy temperature.

\subsection{Crop evapotranspiration}

In Figure 5, the relative evapotranspiration, the ratio of daily evapotranspiration of each treatment to the T1 treatment referred to as $R_{E T}$ hereafter - was used to eliminate the impact of climate on crop ET. It was found that plants during

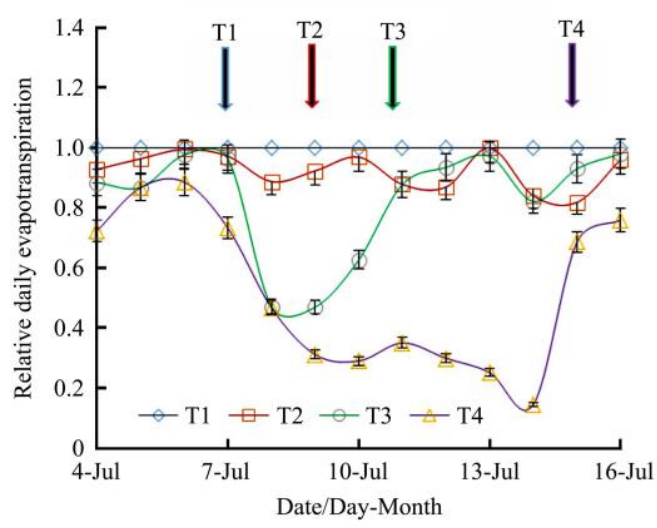

a. First half elongation stage

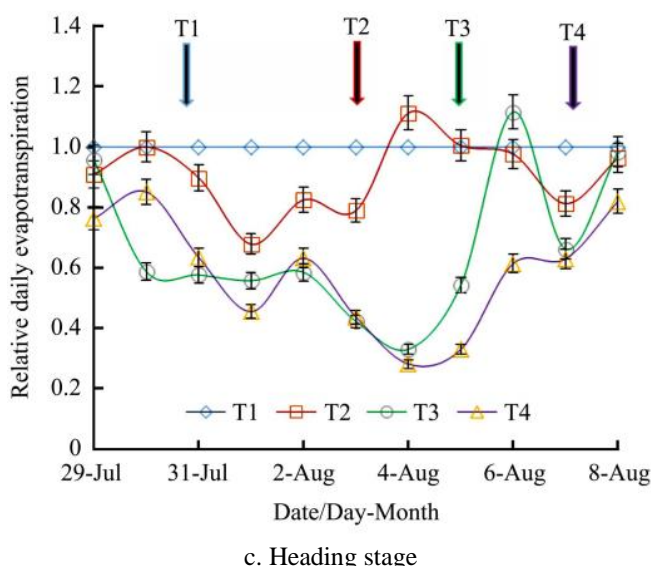

non-irrigation periods had very low crop ET. However, after re-irrigation, crop ET in the $\mathrm{T} 2$ and $\mathrm{T} 3$ treatments increased quickly and reached the values in $\mathrm{T} 1$ treatment. It should be noted that although plants in the T4 treatment were irrigated, their ET was still lower by 20\%-30\% compared to those at T1. This ET pattern is different from the stomatal conductivity response in Figure 3, where stomatal conductivity increased to values reflecting water sufficient conditions. The reason is that after a long period of water stress, a few leaves near the ground surface became withered; therefore, actual transpiration in the leaf area was reduced and ultimately resulted in a small crop ET for the whole plant. Therefore, a short period of water stress may have a slight effect on maize plant $E T$, while a long period of water stress may negatively impact maize plant growth and evapotranspiration.

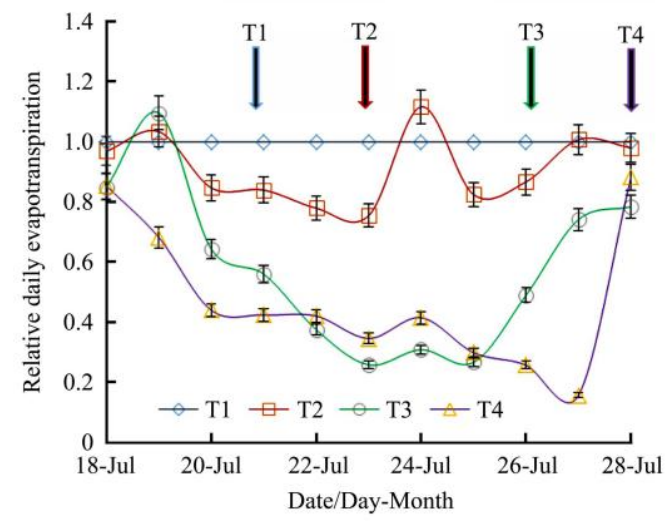

b. Second half elongation stage

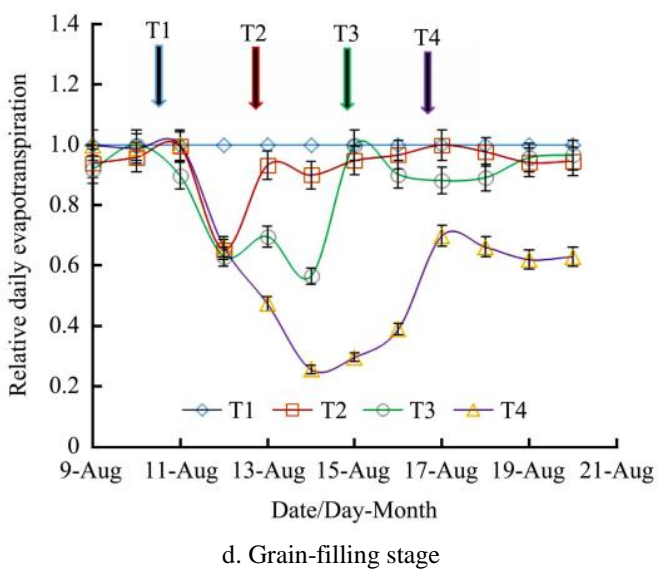

Figure 5 Relative daily evapotranspiration (the ratio of daily evapotranspiration of maize plants for each treatment to T1 treatment) in the four experimental periods in the 2015 season, symbol

Soil water was the only water resource for crop evapotranspiration in this experiment. Therefore, the relationship between crop $R_{E T}$ and soil water content was analyzed, as shown in Figure 6. Generally, crop $R_{E T}$ decreased with a decrease in soil water content, but their relationships varied among different soil water ranges. When the soil water content was greater than $0.20 \mathrm{~cm}^{3} / \mathrm{cm}^{3}$, the maize $R_{E T}$ mostly ranged within $0.9-1.0$ with a mean value of 0.92 , indicating that water content in this range may have a slight effect on maize $E T$. When the soil water content ranged from 0.10 to $0.20 \mathrm{~cm}^{3} / \mathrm{cm}^{3}$, crop $R_{E T}$ decreased with a decrease in the soil water content. When the two-year data were pooled together, the relationship between $R_{E T}$ and soil water content was regressed as $R_{E T}=6.23 S W C-0.32\left(n=209, R^{2}=0.58\right.$, $F<0.001)$. When the soil water content was less than $0.10 \mathrm{~cm}^{3} / \mathrm{cm}^{3}$, the crop $R_{E T}$ was reduced to approximately 0.1 . This represents the re-watering day for the corresponding treatment

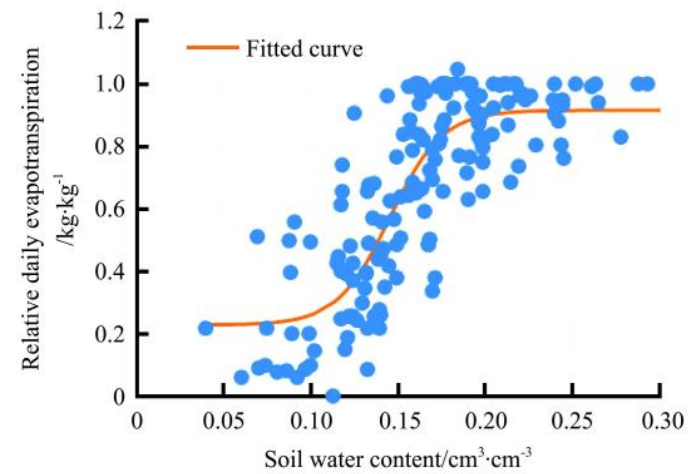

Figure 6 Relationship between soil water content and relative daily evapotranspiration when all data in the 2014 and 2015 seasons were pooled together. The regressed curves were fitted for sigmoid model 
means that plant suffered greatly from severe water stress and its growth system was largely destroyed. We observed that only 2-3 active leaves remained and that the other leaves withered in the T4 treatment at the end of the experimental period at the grain-filling stage in 2015 .

\section{Discussion}

\subsection{Stomatal conductivity and canopy temperature}

High canopy temperature under water stress is mainly due to part of the stoma closing. Therefore, the relationship between stomatal conductivity and $R_{T}$ was analyzed, seeing Figure 7 . It can be seen that stomatal conductivity was negatively related to $R_{T}$ and that stomatal conductivity linearly decreased as $R_{T}$ increased. The slope rates of the regressed lines between stomatal conductivity and $R_{T}$ are close in the 2014 and 2015 seasons. When all data were pooled together, the relationship can be regressed as $g_{s}=979 R_{T}-1225\left(R^{2}=0.61, F<0.001\right)$, where $g_{s}$ is the stomatal conductivity measured at approximately 12:00, $\mathrm{mmol} /\left(\mathrm{m}^{2} \cdot \mathrm{s}\right)$, and $R_{T}$ is the ratio of the canopy to air temperatures measured at approximately 12:00. Similar results were reported by $\mathrm{Han}^{[19]}$ and $\mathrm{Yu}^{[42]}$. They reported that $g_{s}$ decreased with $T_{c}$ and $\Delta T$ increasing.

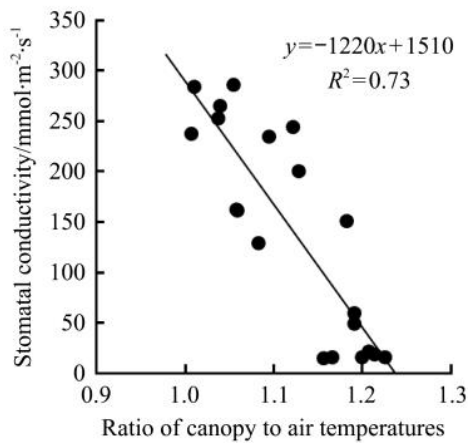

a. 2014 season

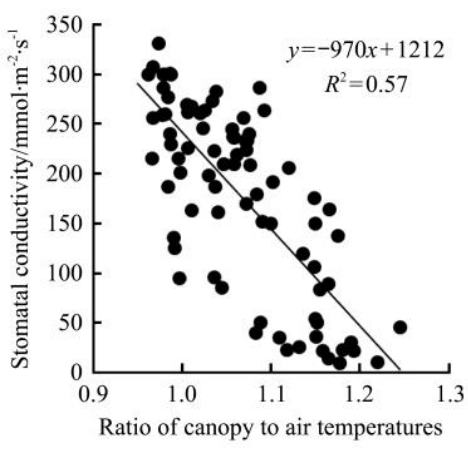

b. 2015 season

Figure 7 Relationship between stomatal conductivity to the ratio of canopy to air temperatures in the 2014 and 2015 seasons

The data in Figures 3 and 4 showed that when the soil water content was greater than $0.22 \mathrm{~cm}^{3} / \mathrm{cm}^{3}$, stomatal conductivity was approximately $300 \mathrm{mmol} /\left(\mathrm{m}^{2} \cdot \mathrm{s}\right)$ and $R_{T}$ was approximately 1.0 , while when the soil water content was lower than $0.15 \mathrm{~cm}^{3} / \mathrm{cm}^{3}$, stomatal conductivity was lower than $50 \mathrm{mmol} /\left(\mathrm{m}^{2} \cdot \mathrm{s}\right)$ and $R_{T}$ was approximately 1.2. Similarly, in Figure 6, the crop ET begins to decrease when the soil water is lower than $0.2 \mathrm{~cm}^{3} / \mathrm{cm}^{3}$ and decreases by approximately $40 \%$ when the soil water is lower than $0.15 \mathrm{~cm}^{3} / \mathrm{cm}^{3}$. It is reported that the net photosynthesis rate of maize leave during the period from elongation to heading stage reached the maximum when soil water content is higher $60 \% \mathrm{FC}$, however, they decreased to approximately zero when soil water content reached $40 \% \mathrm{FC}^{[43,44]}$. These findings are the same as the results of this study. The findings are also in agreement with the data in the "Grades of Meteorological Drought" and "Grade of Agricultural Drought", in which $60 \%$ FC and $40 \%$ FC are the limits to identify the good water and severe water stress condition $^{[33,34]}$. Therefore, the soil water content of $40 \% \mathrm{FC}$ and $60 \% \mathrm{FC}$, correspondingly referring to the $R_{T}$ values of 1.2 and 1.0 , can be used to discriminate severe water stress and well-watered conditions, respectively.

\subsection{Ratio of canopy to air temperatures and CWSI}

The crop water stress index (CWSI) is widely used to evaluate crop water conditions ${ }^{[27,35]}$. In this study, the CWSI was calculated using the data measured in the heading and grain-filling stages in the 2014 and 2015 seasons in Equation (1). The lower limit temperature difference $\left(\Delta T_{L L}\right)$ represents the canopy temperature status under well-watered, non-stress conditions and generally relates to $\mathrm{VPD}^{[36]}$. The measured data in this study were used to develop the relationship between $\Delta T_{L L}$ and $V P D$, and the results are shown in Figure 1. The slope coefficient and interception of this regressed line were -0.913 and 3.74 , respectively. The linear relationship between $\triangle T_{L L}$ and $V P D$ for maize in Antalya of Turkey was $\Delta T_{L L}=1.39-0.86 V P D$ by Irmak et al. ${ }^{[36]}$, and $\Delta T_{L L}=2.14-1.97 V P D$ in North Dakota of the USA by Steele et al. ${ }^{[45]}$ and $\triangle T_{L \mathrm{~L}}=2.73-1.90 \mathrm{VPD}$ in Northeastern Colorado of the USA by Taghvaeian et al. ${ }^{[46]}$ There are differences in intercept and slope coefficient among these researches, mainly because of the variation of climate, soil type, and plant variety ${ }^{[36]}$.

The upper limit temperature difference $\left(\Delta T_{U L}\right)$ represents the temperature of a severely stressed, non-transpiration plant. In this study, the $\Delta T_{U L}$ value was taken from a maize plant in the T4 treatment, where the maize suffered from severe water stress and transpiration reached zero for stomatal conductivity, being lower than $50 \mathrm{mmol} /\left(\mathrm{m}^{2} \cdot \mathrm{s}\right)$. The measured $\Delta T_{U L}$ varied from $3.54^{\circ} \mathrm{C}$ to $6.25^{\circ} \mathrm{C}$ with a mean value of $4.79^{\circ} \mathrm{C}$ (Figure 1). This $\Delta T_{U L}$ value is close to $4.38^{\circ} \mathrm{C}$ reported by Taghvaeian ${ }^{[35]}$ and $4.0^{\circ} \mathrm{C}-5.1^{\circ} \mathrm{C}$ by Irmak et al. ${ }^{[36]}$.

The CWSI and $R_{T}$ at the heading and grain-filling stages in 2015 were compared and the results are presented in Figure 8. It can be seen that CWSI was linearly related to $R_{T}$. The determination coefficients $\left(R^{2}\right)$ of the regressed line in Figure 8 is 0.914 , indicating that $R_{T}$ accounted for $91.4 \%$ of variation in CWSI Therefore, $R_{T}$ can be used to evaluate crop water stress as CWSI does.

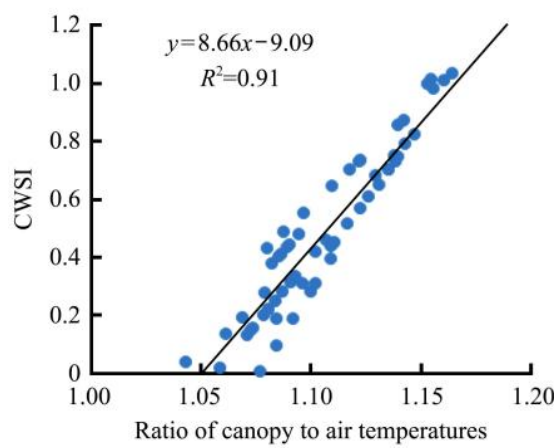

Figure 8 Relationship between crop water stress index (CWSI) and the ratio of canopy to air temperatures at the heading and grain-filling stages in 2015 season

CWSI ranges from 0 to 1 , correspondingly representing non-water stress and severe water stress. Taghvaeian et al. ${ }^{[35]}$ reported that for maize plants with full and high-frequency irrigation, the CWSI generally was lower than 0.3 , while it was 0.3-0.7 under low-frequency irrigation conditions. Carroll et al. ${ }^{[27]}$ 
reported that the average CWSI values varied across irrigation treatments, with 0.37 and 0.54 for glasshouse well-watered and drought and $0.34,0.47$, and 0.51 for field well-watered, drought, and controlled deficit treatments, respectively. Möller et al. ${ }^{[29]}$ reported a CWSI range of 0.4-0.6 for grapevine plants under moderate water stress conditions. These researches show that normally CWSI $<0.3$ can be used as indices of non-water stress conditions. When CWSI is $0.3, R_{T}$ is 1.08 from Figure 8, indicating a good water condition for maize growth based on Figures 3 and 4 , in which $R_{T}$ from 1.2 to 1.0 represent severely water-stressed and well-watered plants. $R_{T}$ value of 1.08 is reaching 1.0, therefore, representing well-watered plants.

To calculate CWSI, the lower and upper limit temperature differences between the canopy and air are always estimated with empirically regressed curves using the vapor pressure deficit and air temperature ${ }^{[35,47-49]}$. These regressed curves may vary according to the climate, region and crops ${ }^{[35,48,49]}$. The indicator of $R_{T}$ can reduce uncertainty from the parameters in these regressed models because all canopy and air temperatures are always directly and simultaneously measured. The consistency of the relationships among $R_{T}$, stomatal conductivity, soil water content and CWSI (Figures 3, 4 and 7) also confirm that using the indices of $R_{T}$ is an optional approach to evaluate maize water stress.

\section{Conclusions}

The main conclusions drawn from the two-year experiment were described as follows:

(1) The highest stomatal conductivity, approximately $300 \mathrm{mmol} /\left(\mathrm{m}^{2} \cdot \mathrm{s}\right)$, was measured under water sufficient conditions and decreased with the water stress duration. Soil water lower than $0.15 \mathrm{~cm}^{3} / \mathrm{cm}^{3}$ resulted in stomatal conductivity of less than $50 \mathrm{mmol} /\left(\mathrm{m}^{2} \cdot \mathrm{s}\right)$, indicating severe water stress condition.

(2) Canopy temperatures and the differences in the canopy and air temperatures increased with the soil water content decreasing but varied according to the environmental conditions. The ratio of the canopy to air temperatures was approximately 1.2 when the soil water content was lower than $0.15 \mathrm{~cm}^{3} / \mathrm{cm}^{3}$ and reached 1.0 under well-watered conditions. Therefore, the ratio value of 1.2 can be used to identify severe water conditions.

(3) Crop evapotranspiration was also decreased with soil water decreasing. ET after re-irrigation for severe water stress treatment further decreased by $20 \%-30 \%$ compared to T1. When the SWC is lower than $0.2 \mathrm{~cm}^{3} / \mathrm{cm}^{3}$, ET linearly decreased with $S W C$ decreases.

(4) $R_{T}$ is closely related to stomatal conductivity and soil water content, and especially linearly related to CWSI. Therefore, the indices of $R_{T}$ are alternative to CWSI for evaluating maize water stress.

\section{Acknowledgements}

This work was supported by the National Nature Science Foundation of China (Grant No. 51939005), the National Key Research and Development Program of China (Grant No. 2017YFD0201500) and the 111 Project (B18006).

\section{[References]}

[1] Sui J, Wang J D, Gong S H, Xu D, Zhang Y Q, Qin Q M. Assessment of maize yield-increasing potential and optimum $\mathrm{N}$ level under mulched drip irrigation in the Northeast of China. Field Crops Research, 2018; 215: $132-139$.

[2] Guo J P, Zhao J F, Xu Y H, Chu Z, Mu J, Zhao Q. Effects of adjusting cropping systems on utilization efficiency of climatic resources in Northeast China under future climate scenarios. Physics and Chemistry of the Earth, Parts A/B/C, 2015; 87-88: 87-96.

[3] Zhao J F, Guo J P, Xu Y H, Mu J. Effects of climate change on cultivation patterns of spring maize and its climatic suitability in Northeast China. Agriculture, Ecosystems \& Environment, 2015; 202: 178-187.

[4] Zhao J F, Guo J P. Multidecadal changes in moisture condition during climatic growing period of crops in Northeast China. Physics and Chemistry of the Earth, Parts A/B/C, 2015; 87-88: 28-42.

[5] Zhao J F, Guo J P, Mu J. Exploring the relationships between climatic variables and climate-induced yield of spring maize in Northeast China. Agriculture, Ecosystems \& Environment, 2015; 207: 79-90.

[6] Liu H J, Liu Y, Zhang L W, Zhang Z J, Gao Z Z. Quantifying extreme climatic conditions for maize production using RZWQM in Siping, Northeast China. Int J Agric \& Biol Eng, 2019; 12(2): 111-122.

[7] Liang L, Li L, Liu Q. Precipitation variability in Northeast China from 1961 to 2008. Journal of Hydrology, 2011; 404(1-2): 67-76.

[8] Zhao $\mathrm{H}$, Xu Z X, Zhao J, Huang W. A drought rarity and evapotranspiration-based index as a suitable agricultural drought indicator. Ecological Indicators, 2017; 82: 530-538.

[9] Yin X, Olesen J E, Wang M, Öztürk I, Zhang H, Chen F. Impacts and adaptation of the cropping systems to climate change in the Northeast Farming Region of China. European Journal of Agronomy, 2016; 78: 60-72.

[10] China National Bureau of Statistics. National Statistics Yearbook Beijing: China Statistics Press, 2018.

[11] Khan M I, Liu D, Fu Q, Saddique Q, Faiz M A, Li T, et al. Projected changes of future extreme drought events under numerous drought indices in the Heilongjiang Province of China. Water Resources Management, 2017; 31(12): 3921-3937.

[12] Kresović B, Tapanarova A, Tomić Z, Životić L, Vujović D, Sredojević Z, et al. Grain yield and water use efficiency of maize as influenced by different irrigation regimes through sprinkler irrigation under temperate climate. Agricultural Water Management, 2016; 169: 34-43.

[13] Wang Y, Janz B, Engedal T, Neergaard A d. Effect of irrigation regimes and nitrogen rates on water use efficiency and nitrogen uptake in maize. Agricultural Water Management, 2017; 179: 271-276.

[14] Grassini P, Cassman K G. High-yield maize with large net energy yield and small global warming intensity. Proceedings of the National Academy of Sciences of the United States, 2012; 109(4): 1074-1079.

[15] Finger R, Hediger W, Schmid S. Irrigation as adaptation strategy to climate change-A biophysical and economic appraisal for Swiss maize production. Climatic Change, 2011; 105(3): 509-528.

[16] Elliott J, Deryng D, Müller C, Frieler K, Konzmann M, Gerten D, et al Constraints and potentials of future irrigation water availability on agricultural production under climate change. Proceedings of the National Academy of Sciences of the United States of America, 2014; 111(9): 3239-3244.

[17] Qi Z, Ma L, C Bausch W, Trout T, Ahuja L, Flerchinger G, et al. Simulating maize production, water and surface energy balance, canopy temperature, and water stress under full and deficit irrigation. Transactions of the ASABE, 2016; 59(2): 623-633.

[18] Kerridge B L, Hornbuckle J W, Christen E W, Faulkner R D. Using soil surface temperature to assess soil evaporation in a drip irrigated vineyard. Agricultural Water Management, 2013; 116: 128-141.

[19] Han M, Zhang H, DeJonge K C, Comas L H, Trout T J. Estimating maize water stress by standard deviation of canopy temperature in thermal imagery. Agricultural Water Management, 2016; 177: 400-409.

[20] Baeza P, Sánchez-de-Miguel P, Centeno A, Junquera P, Linares R, Lissarrague J R. Water relations between leaf water potential, photosynthesis and agronomic vine response as a tool for establishing thresholds in irrigation scheduling. Scientia Horticulturae, 2007; 114(3): 151-158.

[21] Virlet N, Lebourgeois V, Martinez S, Costes E, Labbé S, Regnard J-L. Stress indicators based on airborne thermal imagery for field phenotyping a heterogeneous tree population for response to water constraints. Journal of Experimental Botany, 2014; 65(18): 5429-5442.

[22] Maes W H, Steppe K. Estimating evapotranspiration and drought stress with ground-based thermal remote sensing in agriculture: A review. Journal of Experimental Botany, 2012; 63(13): 4671-4712.

[23] Serrano L, González-Flor C, Gorchs G. Assessing vineyard water status using the reflectance based water index. Agriculture, Ecosystems \& Environment, 2010; 139(4): 490-499. 
[24] Micol R, Cinzia P, Chiara C, Michele M, Lorenzo B, Sergio C, et al. Discriminating irrigated and rainfed maize with diurnal fluorescence and canopy temperature airborne maps. ISPRS International Journal of Geo-Information, 2015; 4(2): 626-646.

[25] Jackson R D, Idso S B, Reginato R J, Pinter P J. Canopy temperature as a crop water stress indicator. Water Resources Research, 1981; 17(4): $1133-1138$

[26] Idso S B, Jackson R D, Pinter P J, Reginato R J, Hatfield J L. Normalizing the stress-degree-day parameter for environmental variability. Agricultural Meteorology, 1981; 24(Supp. C): 45-55.

[27] Carroll D A, Hansen N C, Hopkins B G, DeJonge K C. Leaf temperature of maize and Crop Water Stress Index with variable irrigation and nitrogen supply. Irrigation Science, 2017; 35(6): 549-560.

[28] Stockle C, Dugas W. Evaluating canopy temperature-based indices for irrigation scheduling. Irrigation Science, 1992; 13(1): 31-37.

[29] Möller M, Alchanatis V, Cohen Y, Meron M, Tsipris J, Naor A, et al. Use of thermal and visible imagery for estimating crop water status of irrigated grapevine. Journal of Experimental Botany, 2007; 58(4): 827-838.

[30] Agam N, Cohen Y, Alchanatis V, Ben-Gal A. How sensitive is the CWSI to changes in solar radiation? International Journal of Remote Sensing, 2013; 34(17): 6109-6120.

[31] Lu X, Li Z, Bu Q, Cheng D, Duan W, Sun Z. Effects of rainfall harvesting and mulching on corn yield and water use in the corn belt of Northeast China. Agronomy Journal, 2014; 106(6): 2175-2184.

[32] Liu Y, Li W, Tan J, Liu H. Changing trend of reference crop evapotranspiration and its main influncing factors in the plain area of Jilin province. Journal of Irrigation and Drainage, 2015; 34(Supp. 2): $112-115$

[33] GB/T 20481-2017. Grades of meteorological drought. Beijing: China Standards Press, 2017.

[34] GB/T 32136-2015. Grade of agricultural drought. Beijing: China Standards Press, 2016

[35] Taghvaeian S, Chávez J, Bausch W, DeJonge K, Trout T. Minimizing instrumentation requirement for estimating crop water stress index and transpiration of maize. Irrigation Science, 2014; 32(1): 53-65.

[36] Irmak S, Haman D Z, Bastug R. Determination of crop water stress index for irrigation timing and yield estimation of corn. Agronomy Journal, 2000; 92(6): 1221-1227.

[37] Egea G, Padilla-Díaz C M, Martinez-Guanter J, Fernández J E, Pérez-Ruiz
M. Assessing a crop water stress index derived from aerial thermal imaging and infrared thermometry in super-high density olive orchards Agricultural Water Management, 2017; 187(Supp. C): 210-221.

[38] Cohen S, Moreshet S, Le Guillou L, Simon J-C, Cohen M. Response of citrus trees to modified radiation regime in semi-arid conditions. Journal of Experimental Botany, 1997; 48(306): 35-44

[39] Liu H, Cohen S, Lemcoff J H, Israeli Y, Tanny J. Sap flow, canopy conductance and microclimate in a banana screenhouse. Agricultural and Forest Meteorology, 2015; 201: 165-175.

[40] Dong X, Patton B, Nyren A, Nyren P, Prunty L. Quantifying root water extraction by rangeland plants through soil water modeling. An International Journal on Plant-Soil Relationships, 2010; 335(1): 181-198.

[41] Tron S, Laio F, Ridolfi L. Plant water uptake strategies to cope with stochastic rainfall. Advances in Water Resources, 2013; 53: 118-130.

[42] Yu L Y, Cai H J, Zheng Z, Li Z J, Wang J. Towards a more flexible representation of water stress effects in the nonlinear Jarvis model. Journal of Integrative Agriculture, 2017; 16(1): 210-220.

[43] Feng X, Zhou G. Relationship of leaf water content with photosynthesis and soil water content in summer maize. Acta Ecologica Sinica, 2018; 38(1): 177-185

[44] Wang F, He Q, Zhou G. Leaf water content at different positions and its relationship with photosynthesis when consecutive drought treatments are applied to summer maize from the 3-leaf stage. Acta Ecologica Sinica, 2019; 39(1): 354-264.

[45] Steele D D, Stegman E C, Gregor B L. Field comparison of irrigation scheduling methods for corn. Transactions of the ASAE, 1994; 37(4): 1197-1203.

[46] Taghvaeian S, Chávez J L, Hansen N C. Infrared thermometry to estimate crop water stress index and water use of irrigated maize in Northeastern Colorado. Remote Sensing, 2012; 4(11): 3619-3637.

[47] DeJonge K C, Taghvaeian S, Trout T J, Comas L H. Comparison of canopy temperature-based water stress indices for maize. Agricultural Water Management, 2015; 156: 51-62.

[48] Alves I, Pereira L S. Non-water-stressed baselines for irrigation scheduling with infrared thermometers: A new approach. Irrigation Science, 2000; 19(2): 101-106.

[49] Payero J O, Neale C M U, Wright J L. Non-water-stressed baselines for calculating crop water stress index (CWSI) for alfalfa and tall fescue grass. Transactions of the ASAE, 2005; 48(2): 653-661. 